\title{
Outcomes of children with attention deficit/ hyperactivity disorder: global functioning and symptoms persistence
}

\author{
Ahmed Al Ansari ${ }^{1}$, Randah R. Hamadeh ${ }^{1}$, Haitham Jahrami ${ }^{2}$ and Eman A. Haji ${ }^{2}$
}

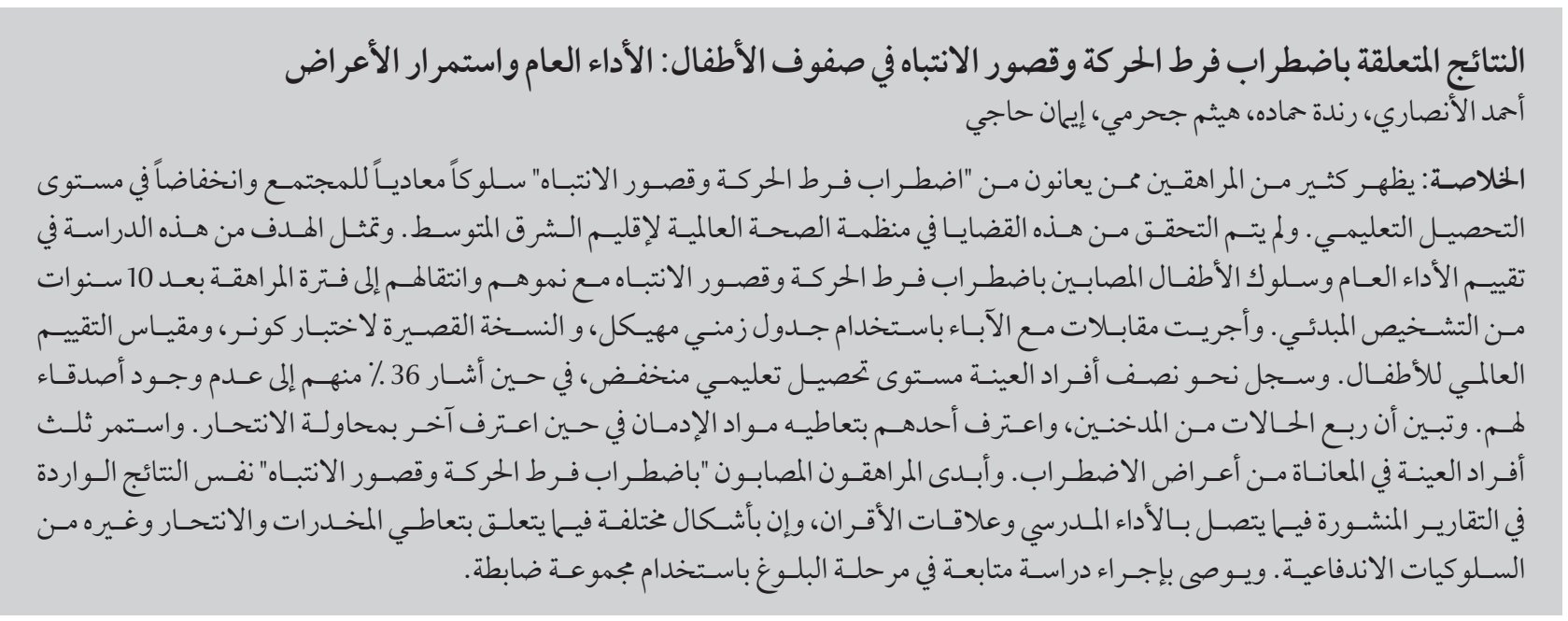

ABSTRACT Many adolescents with ADHD show antisocial behaviour and low educational achievement. These issues have not been validated in the World Health Organization Eastern Mediterranean Region. The objective of this study was to assess the global functioning and behaviour of children with ADHD growing into adolescence 10 years after initial diagnosis. Parents were interviewed using a structured questionnaire, Conner's Short Version Test and the Children's Global Assessment Scale. Nearly half of our sample had low academic achievement and $36 \%$ had no friends. A quarter of the cases were smokers, one admitted abusing drugs and one had attempted suicide. One third of the sample continued to have ADHD symptoms. Adolescents with ADHD had similar school performance and peer relationships to those reported previously, but differences with regard to drug use, suicide and other impulsive behaviour. A follow-up study into adult life using a control group is recommended.

\section{Impact du trouble de déficit de l'attention avec hyperactivité chez l'enfant : fonctionnement général et} persistance des symptômes

RÉSUMÉ De nombreux adolescents affectés par le trouble de déficit de l'attention avec hyperactivité (TDAH) montrent des comportements antisociaux et des faibles résultats scolaires. Ces problèmes n'ont pas été validés dans la Région de la Méditerranée orientale de l'Organisation mondiale de la Santé. L'objectif de la présente étude était d'évaluer le fonctionnement général et le comportement des enfants passés à l'adolescence 10 ans après le diagnostic initial du TDAH. Les parents ont été interrogés au moyen d’un questionnaire structuré, de la version abrégée du questionnaire de Conners et de l'échelle d'évaluation globale du fonctionnement de l'enfant. Près de la moitié de l'échantillon avait des faibles résultats scolaires et $36 \%$ n'avaient pas d'amis. Un quart des cas étaient des fumeurs, un d'entre eux avait admis l'usage de substances psychoactives et un autre avait fait une tentative de suicide. Un tiers de l'échantillon avait continué d'avoir des symptômes du TDAH. Les adolescents affectés par le TDAH avaient les mêmes performances scolaires et les mêmes relations avec les pairs que dans les rapports publiés. Par contre, ils avaient des représentations différentes en ce qui concerne la consommation de drogues, le suicide ainsi que d'autres comportements impulsifs. Une étude de suivi menée à l'âge adulte à l'aide d'un groupe témoin a été recommandée.

${ }^{7}$ College of Medicine and Medical Sciences, Arabian Gulf University, Manama, Bahrain. (Correspondence to: R.R. Hamadeh: randah@agu.edu. bh). ${ }^{2}$ Ministry of Health, Manama, Bahrain.

Received: 22/08/16; accepted: 15/01/17 


\section{Introduction}

Attention deficit hyperactivity disorder (ADHD) is the most common psychiatric disorder encountered among children with disruptive behaviour (1). The disorder affects $3-7 \%$ of schoolaged children (2). Several studies have shown the persistence of ADHD symptoms intoadolescence and adult life with prevalence rates that vary according to several factors including age, gender and presenting symptoms (3-6). Some studies have suggested that symptom severity and early onset are prognostic factors regardless of treatment type (7-10). Adolescents with ADHD show academic underachievement in comparison to their non-ADHD peers (11-13). They are at increased risk of developing mental health and behavioural problems $(14,15)$. Furthermore, social problems such as rejection by peers and inability to maintain friendships complicate the learning process further and lead to decreased motivation to study and increase the chance of school dropout (16). The presence of ADHD in childhood increases the risk of developing antisocial behaviour and substance abuse later in adolescence, which in turn increases the risk of delinquency, such as increased number of arrest records, conviction and imprisonment (17).

Prevalence data on ADHD in the Middle East vary: Saudi Arabia (16.3\%), United Arab Emirates (1.0\%), Qatar (9.4\%), Yemen (1.3\%), Oman (8.2\%) and Palestine (4.3\%) (18). However, published data on ADHD follow-up studies in the World Health Organization (WHO) Eastern Mediterranean Region are lacking. Data on the prevalence rate of $\mathrm{ADHD}$ in Bahrain are not available and outcome studies are not reported in the Region, however, it was estimated that $20 \%$ of the new referrals had a diagnosis of ADHD at the Child and Adolescent Psychiatric Unit (CAPU) in 2011 at the Bahrain Psychiatric Hospital (19). The CAPU has been the main facility for children with psychiatric and behavioural problems in Bahrain since 1981. The Unit has a busy outpatient clinic (400 new referrals and $>2000$ visits annually) and an inpatient unit/day care programme of 12-bed capacity for children aged $\leq 12$ years. Bahrain is an archipelago situated in the Arabian Gulf Region, east of Saudi Arabia. It covers an area of $\sim 765 \mathrm{~km}^{2}$, and had an estimated population of 1.37 million in 2015. Non-Bahrainis represented $52.7 \%$ of the population with a male to female ratio of 2.5 .

The purpose of the present study was to assess the global functioning and behaviour of a cohort of $\mathrm{ADHD}$ patients in Bahrain diagnosed in childhood and later examined in adolescence.

\section{Methods}

This was a cross-sectional study of 46 children aged 6-8 years who were diagnosed with ADHD at CAPU in 2004-2006 based on the Diagnostic and Statistical Manual of Mental Disorders, 4th Edition criteria and Conner's Rating Scale - Revised for Parents and Teachers $(2,17)$. Thirty-three (71.9\%) patients and their parents were interviewed in winter 2015. Thirteen (28\%) of the cases were unreachable due to outdated contact details. None of the patients or their parents refused to participate. ADHD patients who had low cognitive ability (intelligence quotient $<80$ ) and/or received a dual diagnosis of autism spectrum disorders (ASDs) were excluded.

The data for this research were collected from the parents of children with $\mathrm{ADHD}$, and no questioning was directed to the children themselves. The parents were interviewed face-to-face $(n=5)$ or by telephone $(n=28)$; during the interviews the children were aged $10-12$ years, following their initial diagnosis by 1 team member. The researcher followed a structured interview questionnaire designed for the study, completed the Conner's Test - Short Version (20), a 30-point scale to detect $\mathrm{ADHD}$ symptoms, and the Child Global Assessment Scale (C-GAS) for functional impairment (21). The study questionnaire was designed to obtain information, regarding demographic data for patients and their parents, presence of ADHD symptoms and educational status. History of substance use and smoking, history of juvenile justice involvement, suicide and suicide attempts, risk-taking behaviour in the last 12 months, and lifestyle dimensions including relationships, weight, sleep and eating habits were also collected. The questionnaire also included a section on treatment duration and type, and parents' views of their children's outcomes during the study period. The interview lasted 45 minutes. Social class was defined following a modified Hollingshead and Redlich 5-point Likert scale with class 1 being high and 5 low (22).

Ethical approval was obtained from the Research Technical and Support Committee, Ministry of Health, Bahrain. Study participation was voluntary and each participant gave signed consent.

Data analysis was mostly descriptive using IBM SPSS Statistics version 22. Counts and percentages for each distinct value found for a variable were displayed in a frequency table. The $\chi^{2}$ or Fisher's exact test was used to measure the association between 2 categorical variables.

\section{Results}

Patients' demographic data are presented in Table 1. Boys $(n=25)$ outnumbered girls $(n=8)$ and accounted for $75.8 \%$ of the study population, with a male to female ratio of $3: 1$. The mean age at diagnosis was 7.3 [standard deviation (SD) 2.4] years and the mean current age 16.9 (1.9) years. Fourteen (42.4\%) had inappropriate educational 


\begin{tabular}{|c|c|c|}
\hline \multicolumn{3}{|l|}{ Table 1 Demographic Data } \\
\hline Patient characteristics & No. & $\%$ \\
\hline \multicolumn{3}{|l|}{ Sex } \\
\hline Male & 25 & 75.8 \\
\hline Female & 8 & 24.2 \\
\hline \multicolumn{3}{|l|}{ Educational level } \\
\hline Age appropriate & 19 & 57.6 \\
\hline Not appropriate for age & 14 & 42.4 \\
\hline \multicolumn{3}{|l|}{ Employment } \\
\hline Employed & 2 & 6.1 \\
\hline Unemployed & 6 & 18.2 \\
\hline Student & 25 & 75.8 \\
\hline \multicolumn{3}{|l|}{ Social Class } \\
\hline 1st & 0.0 & 0.0 \\
\hline 2nd & 6 & 18.2 \\
\hline $3 r d$ & 8 & 24.2 \\
\hline 4 th & 17 & 51.5 \\
\hline 5 th & 2 & 6.1 \\
\hline \multicolumn{3}{|l|}{ Consanguinity } \\
\hline First degree & 6 & 18.2 \\
\hline Second degree & 3 & 9.1 \\
\hline No relation & 24 & 72.7 \\
\hline \multicolumn{3}{|l|}{ Birth order } \\
\hline First & 13 & 39.4 \\
\hline Last & 5 & 15.2 \\
\hline Other & 15 & 45.5 \\
\hline \multicolumn{3}{|l|}{ Birth type } \\
\hline Normal delivery & 27 & 81.8 \\
\hline Caesarean section & 3 & 9.1 \\
\hline Difficult labour & 3 & 9.1 \\
\hline Total & 33 & 100.0 \\
\hline
\end{tabular}

level for their age that was determined using a cutoff of 2 academic years/ standards below the expected grade for their age. Twenty-five (75\%) of the patients were still students, with only 2 holding a regular job, and another 6 were neither in school nor working. More than half of the patients belonged to lower social classes 4 and 5 and a quarter were from class 3. Most patients were either first or last born (85\%) and had a normal delivery (82\%), and more than a quarter had related parents (27\%). None of the patients were engaged or married or died from accident or suicide. There was only 1 attempted suicide by overdose of paracetamol.
Six cases $(18.2 \%)$ received medication only, 17 (51.5\%) behavioural therapy only and $10(30.3 \%)$ combination treatment. Only 3 cases (9\%) did not receive any treatment after completing their evaluation. Treatment duration was 6 months $(\mathrm{n}=22,66 \%), 1$ year $(\mathrm{n}=$ 4, 12.1\%), 2 years $(n=2,6.1 \%), 3$ years $(\mathrm{n}=1,3 \%)$ and $\geq 4$ years $(\mathrm{n}=4,12.1 \%)$. Thirty-one (94\%) parents, mostly mothers, reported improvement in their children's conditions and the rest reported no change. The mean score for the Conner's Test Short Version was 13.1 (4.5). The C-GAS score was "absent-no symptoms" in 20 (60\%) patients. Symptoms were present in 12 (33.4\%) patients and 1 (6.6\%) patient scored major impairment. Although the study sample was small we compared those who were symptom free with those who still had symptoms according to Conner's Test Short Version, using 15 points as the threshold, and those who were impaired with C-GAS $\leq$ 80 points compared to those who were not impaired with C-GAS $>80$, to ascertain differences between the persistent group and the dissentient group. The $\chi^{2}$ test showed a nonsignificant $P$ value for both comparisons.

\section{Discussion}

The gender ratio and social class of the nonrespondents were not different from the interviewed sample. The male to female ratio of 3: 1 was similar to the worldwide gender representation among ADHD cohorts (23). Nearly half of the patients had educational underachievement; something expected and frequently reported in the literature $(11,14)$. The majority of patients were students, with a mean age of 17 years. The number of patients holding a regular job was small and comparable to that in similar age groups in other studies and national statistics (24). The social class representation among the sample was half from lower social classes and 
a quarter from the middle class; similar to that reported for the child psychiatry population attending the same clinic (19).

The birth history including the rate of caesarean section delivery was in agreement with internationally acceptable ratios (25). The rate of caesarean section delivery was lower by more than half that of patients with ASDs attending the same clinic (26). However, the rate of consanguineous marriages among the parents of ADHD patients was similar to that reported in the general population and among patients with ASDs $(26,27)$.

The number of persons aged $\leq 17$ years in the general population who are engaged in deliberate self-harm or who have committed suicide is small, hence it was not surprising to find a low rate of suicide among the study sample (28). Adolescents in Bahrain are permitted to obtain a driving licence at age 18 years; therefore, the question about road traffic accidents might not have been appropriate at this stage. The number of patients who abused drugs was low in comparison to that reported in western countries, although we do not have figures for this variable in the community to make accurate comparisons. The hospital records were the only available source of information about drug use and they showed a low prevalence rate of drug use among adolescents, with the vast majority aged $>18$ years. Glue solvents and cannabis were the main types of drugs misused by the adolescent population. It seems that drug addiction among them is only well established after the age of 18 years due to availability and financial reasons.

The number of ADHD patients who have ever smoked was high at $27.3 \%$, and it was even higher than that reported in the same age group in the general population (29). Adolescents who had ADHD with a focus on attention symptoms were 3 times more likely to start smoking than their unaffected peers $(30,31)$. We should take into consideration that smoking is generally higher among men and most smokers in our study were male.

The number of patients who reported no same-sex friendship was higher (36\%) than that reported for their peers in high school by school counselling services.

We do not have national figures to compare rates of eating and sleeping problems. Our figures for eating disorders among ADHD patients were similar to those in a cohort of ASD patients, however, our figures for sleep problems differed $(32,33)$. Patients with ASDs have reported more sleep problems (40\%) than ADHD patients have (9.0\%) (34). Weight-related problems (18\%) were similar to those reported for the WHO Eastern Mediterranean Region (15.6\% and $17.4 \%$ among boys and girls, respectively) (30). A recent study conducted on 1 st year medical students showed a rate of sleep-related disorders of $43 \%$ compared to $9 \%$ in our sample (31). We are aware of the fact that discussing these variables can only be accurately addressed in the presence of a community control group.

Most of our patients received behaviour therapy only, while one third received a combination of both treatments. Recently, parents of ADHD patients have been requesting psychosocial treatment more often because of fear of adverse drug effects. Noncompliance to treatment is reported to be high among ADHD patients and their parents $(31,35)$. Two thirds of our sample continued treatment for 6 months only; the percentage fell to $12 \%$ by the end of the 1st year and continued at the same rate for the next 3 years. Patients with severe impairments adhered better to follow-up appointments than those with mild or moderate symptoms.
The majority of mothers of ADHD patients reported improvement in the condition of their children. It was totally subjective in nature and no effort was made to confirm the improvement objectively by the investigators. Two thirds of the sample scored $>60$ on the C-GAS, which meant no significant symptoms. However, some symptoms persisted in one third and severe impairment in 3\%. This is in accordance with other reported studies (3-5).

The study had some limitations including the absence of a control group. Furthermore, the small sample size made it difficult to perform detailed analysis. Data for the 13 excluded cases might have differed from the study sample data, although the excluded cases were similar in gender and social class distribution to those included in the study.

In conclusion, our cohort of 33 ADHD cases diagnosed in childhood and followed into adolescence showed that the symptoms persisted in one third of cases. Patients were mostly students living at home with considerable educational underachievement, few friends, and were cigarette smokers. Few patients had legal issues, attempted suicide or abused alcohol or drugs. These findings can be explained by the fact that Bahrain has a low rate of suicide and aggressive behaviour. These preliminary findings need to be supported by a long follow-up study that includes a control group.

\section{Acknowledgements}

The authors would like to acknowledge the valuable work of Mrs. Nada Abdulrahman for her help in data collection.

Funding: None.

Competing interests: None declared. 


\section{References}

1. McArdle P, Prosser J, Kolvin I. Prevalence of psychiatric disorder with or without psychosocial impairment. Eur Child Adolesc Psychiatry. 2004 Dec;13(6):347-53. PMID:15619046

2. Diagnostic and statistical manual for mental disorders, 4th edition, text version DSM - IV -TR. Arlington, VA: American Psychiatric Association; 2002.

3. Barkley RA, Fischer M, Smallish L, Fletcher K. The persistence of attention-deficit/hyperactivity disorder into young adulthood as a function of reporting source and definition of disorders. J Abnorm Psychol. 2002 May;111(2):279-89. PMID:12003449

4. Rasmussen P, Gillberg C. Natural outcome of ADHD with developmental coordination disorder at age 22 years: a controlled, longitudinal, community based study. J Am Acad Child Adolesc Psychiatry. 2000 Nov;39(11):1424-31. PMID:11068898

5. Caye A. Spadini AV, Karam RG, Grevet EH, Rovaris DL, Bau $\mathrm{CH}$ et al. Predictors of persistence of ADHD into adulthood: a systematic review of the literature and meta-analysis. Eur Child Adolesc Psychiatry. 2016 Nov;25(11):1151-9. PMID:27021056

6. Biederman J, Petty CR. Woodworth KY, Lomedico A, Hyder LL, Faraone SV. Adult outcome of attention-deficit/hyperactivity disorder: a controlled 16 years follow-up study. J Clin Psychiatry. 2012 Jul;73(7):941-50. PMID:22901345

7. Lara C, Fayyad J, Grapp R. Childhood predictors of adult ADHD: result from the WHO world Mental Health (WMH) survey initiative. Biol Psychiatry. 2009 Jan 1;65(1):40-54. PMCID:PMC2629074

8. Molina BS, Hinshaw SP, Swanson JM, Arnold LE, Vitiello B, Jensen PS, et al.; MTA Cooperative Group. The MTA at 8 years: prospective follow-up of children treated for combined-type ADHD in a multisite study. J Am Acad Child Adolesc Psychiatry. 2009 May;48(5):485-500. PMID:19318991

9. Sciberras E, Roos LM, Efron D. Review of Prospective Longitudinal studies of children with ADHD: Mental health, educational and social outcomes. Curr Atten Disord Rep. 2009 Dec;1(4):171-7.

10. Mannuzza S, Klein RG, Moulton JL 3rd. Persistence of attention-deficit/hyperactivity disorder into adulthood: what have we learned from prospective follow-up studies? J Atten Disord. 2003 Nov; 7(2):93-9. PMID:15018358

11. Leo IM, Feldman HM. Academic and educational outcomes of children with ADHD. J Pediatr Psychol. 2007 Jul;32(6):643-54. PMID:17569716</jrn>

12. Kuriyan AB, Pelham WE Jr, Molina BSG, Waschbusch DA, Gnagy EM, Sibley $\mathrm{MH}$, et al. Young adult educational and vocational outcomes of children diagnosed with ADHD. J Abnorm Child Psychol. 2013 Jan;41(1):27-41. PMID:22752720

13. Hechtman L, Swanson JM, Sibley MH, Stehli A, Owens EB, Mitchell JT, et al. Functional adult outcomes 16 years after childhood diagnosis of attention-deficit/hyperactivity disorder: MTA results. J Am Acad Child Adolesc Psychiatry. 2016 Nov:55(1):945-52. PMID:27806862

14. Efron D, Sciberras E. The diagnostic outcomes of children with suspected attention deficit hyperactivity disorder following multidisciplinary assessment. J Paediatr Child Health. 2010 Jul;46(7-8):392-7. PMID:20546102

15. Elia J, Ambrosini P, Berrettini W. ADHD characteristics: I. Concurrent co- morbidity patterns in children \& adolescents. Child Adolesc Psychiatry Ment Health. 2008 Jul 3;2(1):15. PMID:18598351

16. Murg, Molina BSG, Hoza B, Gerdes AC, Hinshaw SP, Hechtman $\mathrm{L}$, et al. Peer rejection and friendships in children with Attention - Deficit /hyperactivity Disorders: Contributions to long-term outcomes. J Abnorm Child Psychol. 2012 Aug;40(6):1013-26. PMID:22331455
17. Mannuzza S, Klien RG. Moulton JL 3rd. Lifetime criminality among boys with ADHD: a prospective follow-up study into adulthood using official arrest records. Psychiatry Res. 2008 Sep 30;160(3):237-46. PMID:18707766

18. Thabet AM, Al Ghamdi H, Abdulla T, Elhelou MW, Vostanis P. Attention, deficit-hyperactivity symptoms among Palestinian children. East Mediterr Health J. 2010 May;16(5):1-12. PMID:20799549

19. Al-Ansari AMS. Characteristics of child and adolescent populations visiting a public child and adolescent psychiatric clinic in Bahrain: a 30-year comparative analysis. Arab J Psychiatry. 2015 May;26(1):32-8.

20. Conners CK. Conners 3rd Edition Manual. Toronto: MultiHealth Systems; 2008.

21. Shaffer D, Gould M, Brasic J, Ambrosini P, Fisher P, Bird H, et al. A children's global assessment scale (C-GAS). Arch Gen Psychiatry. 1983 Nov;40(11):1228-31.

22. Hollingshead $A B$, Ridlich FC. Social class and mental illness. New York: Wiley; 1958.

23. Polanczyk G, De Lima MS, Horta BL, Biederman J, Rohde LA. The worldwide prevalence of ADHD: a systematic review and metaregression analysis Am J Psychiatry 2007 Jun;164(6):9428. PMID:17541055

24. Harpin VA. The effect of ADHD on the life of an individual their family, and community from preschool to adult life. Arch Dis Child. 2005 Feb;90 Suppl 1:12-7. PMID:15665153

25. The National Sentinel Section Audit Report. London: Royal College of Obstetricians and Gynaecologists, 2001.

26. Al Ansari AM, Ahmed MM. Epidemiology of autistic disorder in Bahrain: prevalence and obstetric and familial characteristics. East Mediterr Health J. 2013 Sep;19(9):769-74. PMID:24313037

27. Roy A, Hechtman L, Arnold LE, Sibley MH, Molina BS, Swanson $J M$, et al. Childhood factors affecting persistence and desistence of attention-deficit/hyperactivity disorders symptoms in adulthood: results from MTA. J Acad Child Adolesc Psychiatry. 2016 Nov;55(11):937-44. PMID:27806861

28. Al Arrayed SS. The frequency of consanguineous marriage in the State of Bahrain. Bahrain Med Bull. 1995:17:63-6.

29. Al Ansari AMS, Hamadeh RR, Ali MK, Eloffi A. Suicide in Bahrain in the last decade. Crisis. 2007;28(1):11-5. PMID:17555028

30. Alsayyad J, Omran A, Amin FA, Hamadeh RR, editors. National non-communicable diseases risk factors survey 2007. Bahrain: Ministry of Health; 2010 (http://www.who.int/chp/ steps/2007_STEPS_Survey_Bahrain.pdf, accessed 12 May 2017).

31. Tercyak KP, Leman C, Audrian J. Association of attention deficit disorder with levels of cigarette smoking in a community sample of adolescents. Am Acad Child Adolesc Psychiatry. 2002 Jul;41(7):799-805. PMID:12108804

32. Alzayani S, Hamadeh RR. Sleeping patterns among medical students in the Middle East: identifying areas for intervention. Adv Res. 2015;5(6):1-7.

33. Musaiger AO, Al-Mannai MA. Factors related to weight status of the adult Bahraini population (a community based study). Bahrain Med Bull. 2000;22(3):119-22.

34. Al Ansari AMS, Al Khunaizi M. Non-compliance of children with ADHD to outpatient clinic appointments at the psychiatric Hospital, Kingdom of Bahrain. J Bahrain Med Soc. 2014;25(2):98-100.

35. Swanson J. Compliance with stimulants for attention deficit/ hyperactivity disorder: issues and approaches for improvement. CNS Drugs. 2013;17(2):117-31. PMID:12521359 